\title{
A conquista do direito à moradia no meio rural; proposta de construção de um indicador
}

\author{
BROSLER, Taísa M. ${ }^{1}$ \\ BERGAMASCO, Sonia M. P. P. ${ }^{2}$ \\ 1Faculdade de Engenharia Agrícola, Universidade Estadual de Campinas, Campinas, Brasil. taisamb@terra.com.br \\ 2Faculdade de Engenharia Agrícola, Universidade Estadual de Campinas, Campinas, Brasil. sonia@feagri.unicamp.br
}

\begin{abstract}
Resumo
$\mathrm{O}$ direito à moradia deve ser reconhecido e protegido na esfera internacional e constitucionalmente assegurado, dado o seu posicionamento como direito fundamental na constituição brasileira. Porém, uma moradia adequada continua fazendo parte da luta diária das populações do meio rural. Assim, a pesquisa teve como objetivo elaborar um indicador que mensura o grau de conquista do direito à moradia no meio rural, a partir das especificidades colocadas pela ONU para uma moradia adequada. A formulação desse indicador foi feita através da realização de análise multivariada nos dados obtidos por meio de questionários aplicados em um assentamento de reforma agrária e um bairro rural, ambos localizados no estado de São Paulo. Para complementar e auxiliar na compreensão desses resultados, entrevistas foram realizadas com famílias identificadas durante a aplicação dos questionários. Os fatores de saída da análise mostraram-se consistentes e representativos das realidades encontradas, possibilitando refletir sobre os principais problemas existentes para que a população rural alcance o direito à moradia adequada.
\end{abstract}

Palavras-Chave: habitação rural, indicadores sociais, análise multivariada

\begin{abstract}
The housing right must be recognized and protected at the international level and constitutionally guaranteed due to be a fundamental right in the Brazilian constitution. However, an adequate housing remains part of the daily struggle of the rural population. Therewith, this research aimed to develop an indicator that measures the achievement of the housing right in rural areas, from the specifics raised by the UN to an adequate housing. The formulation of this indicator has been performed by multivariate analysis on data obtained from questionnaires applied in a land reform settlement as well as in a rural district, both in São Paulo state. Also to complement and assist in understanding these results, interviews have been conducted with families identified during the questionnaires. The output factors were consistent and representative of the realities, enabling to reflect on the main problems for the rural population to reach the right to adequate housing.
\end{abstract}

Key-Words: rural housing, social indicators, multivariate analysis 


\section{Introdução}

Postulada como direito humano (Declaração Universal dos Direitos Humanos da ONU de 1948), o direito à moradia deve ser reconhecido e protegido na esfera internacional e constitucionalmente assegurado, dado o seu posicionamento como direito fundamental na atual constituição brasileira (Constituição Federal de 1988).

Este direito não pode ser confundido com o direito de habitação, pois a moradia possui bens externos (objetos) e internos (personalidade humana). Portanto, o direito a esta trará consigo uma referência à "essencialidade do indivíduo", enquanto garantia de um mínimo vital para que o indivíduo possa ser o que ele é, sobreviver e adquirir bens (SOUZA, 2008; MILAGRES, 2011).

A moradia precisa ser compreendia, então, como um espaço de reprodução da pessoa humana, no reconhecimento de sua função social o direito de existência prevalece sobre o ato de morar, pois está no direito de ocupar um lugar no espaço.

Sarlet (2003, p. 20) apresenta ainda que a garantia do direito à moradia traz consigo a libertação da opressão social e da condição de "necessidade" e que este direito deve ser buscado através das particularidades de cada país e região, no contexto local, "já que é na realidade concreta de quem mora e onde mora que se pode aferir a compatibilidade da moradia com uma existência digna". Assim, reforçar a conquista desse direito, a sua efetivação, é considera-la uma primazia a todos os seres humanos e sua garantia deve estar relacionada não somente a sua obtenção como também a sua qualidade, observando os critérios mínimos de saúde para uma moradia digna e a sua representatividade cultural e social para os sujeitos que a habitam.

A efetivação do direito à moradia dependerá, portanto, da resolução da problemática não só da falta de moradia, mas, também, e com significante destaque, do elevado índice de inadequação das moradias, seja nas questões de insalubridade (péssimas condições de higiene), precariedade (grau de risco ao morador), ilegalidade (inexistente juridicamente) ou irregularidade (contrária às normas jurídicas) (HENKES, 2005).

Portanto, damos ênfase na necessidade de se discutir a importância de uma política para a conquista do direito à moradia e não sucintamente uma política habitacional, a qual vê em sua eficácia o aspecto material da habitação.

A conquista da moradia está estreitamente vinculada ao acesso a terra, pois é nela que se construirá a habitação, sendo assim, sua condição e garantia está proeminentemente caracterizada, para o meio rural brasileiro, por exploração e expropriação advindos da acumulação de capital, na valorização da terra como mercadoria.

A partir disso, foi feita a proposta desse trabalho de pesquisa, com o intuito de retratar as condições das famílias que vivem em áreas rurais quanto à conquista do direito à moradia, trazendo reflexões que possibilitam aos órgãos responsáveis a criação e o desenvolvimento de políticas públicas direcionadas à habitação condizentes com a realidade rural brasileira.

\section{Indicador de Conquista do Direito à Moradia}

Esse trabalho teve como proposta principal a elaboração de um indicador pautado nas diretrizes da ONU sobre o que consiste o direito à moradia adequada, para que se obtivesse uma análise do que influencia a conquista do direito à moradia para o meio rural.

Baseada em metodologias sugeridas por Jannuzzi (2009) e Cendrero Uceda (1997), a definição de indicador serve para orientar a discussão ou mesmo a criação de políticas públicas fundamentadas em características determinantes do meio, sendo uma forma de tornar tangível algo que está escrito na sociedade.

Para tanto, utilizou-se como base o próprio documento elaborado pelo Programa das Nações Unidas para Assentamentos Humanos e pela Comissão das Nações Unidas para os 
Direitos Humanos para o Monitoramento do direito à moradia (UN-HABITAT e OHCHR, 2003).

Segundo Barbo e Shimbo (2006, p. 94), captar as várias formas de morar é "uma tarefa complexa, que passa pela definição de um padrão mínimo de moradia digna". Além disso, Jannuzzi (2009) atenta para a dependência desse conceito às apreciações subjetivas dos moradores e, como dados sobre a satisfação declarada pelos moradores acerca de suas moradias, bairro, facilidades de transporte, compra etc. não estão disponíveis, os indicadores acabam sendo construídos com base nas informações objetivas levantadas pelos censos e pesquisas amostrais.

Com isso, foi feita a proposta da elaboração de um questionário tendo como objetivo detalhar, através de questões objetivas e subjetivas, cada diretriz apontada pela ONU para um direito à moradia adequada, sendo elas (texto retirado na íntegra da Relatoria Especial do Conselho de Direitos Humanos da ONU):

- Segurança de posse (SEGPOSSE): Todas as pessoas têm o direito de morar sem o medo de sofrer remoção, ameaças indevidas ou inesperadas.

- Disponibilidade de serviços, infraestrutura e equipamentos públicos (DISPONIB): A moradia deve ser conectada às redes de água, saneamento básico, gás e energia elétrica; em suas proximidades deve haver escolas, creches, postos de saúde, áreas de esporte e lazer e devem estar disponíveis serviços de transporte público, limpeza, coleta de lixo, entre outros.

- Custo acessível (CUSTO): O custo para a aquisição ou aluguel da moradia deve ser acessível, de modo que não comprometa o orçamento familiar e permita também 0 atendimento de outros direitos humanos, como o direito à alimentação, ao lazer etc. Da mesma forma, gastos com a manutenção da casa, como as despesas com luz, água e gás, também não podem ser muito onerosos.
- Habitabilidade (HABIT): A moradia adequada tem que apresentar boas condições de proteção contra frio, calor, chuva, vento, umidade e, também, contra ameaças de incêndio, desmoronamento, inundação e qualquer outro fator que ponha em risco a saúde e a vida das pessoas. Além disso, o tamanho da moradia e a quantidade de cômodos (quartos e banheiros, principalmente) devem ser condizentes com o número de moradores. Espaços adequados para lavar roupas, armazenar e cozinhar alimentos também são importantes.

- Não discriminação e priorização de grupos vulneráveis (GRUPOSVUL): A moradia adequada deve ser acessível a grupos vulneráveis da sociedade, como idosos, mulheres, crianças, pessoas com deficiência, pessoas com HIV, vítimas de desastres naturais etc. As leis e políticas habitacionais devem priorizar 0 atendimento a esses grupos e levar em consideração suas necessidades especiais. Além disso, para realizar o direito à moradia adequada é fundamental que o direito a não discriminação seja garantido e respeitado.

- Localização adequada (LOCADEQ): Para ser adequada, a moradia deve estar em local que ofereça oportunidades de desenvolvimento econômico, cultural e social. Ou seja, nas proximidades do local da moradia deve haver oferta de empregos e fontes de renda, meios de sobrevivência, rede de transporte público, supermercados, farmácias, correios, e outras fontes de abastecimento básicas. A localização da moradia também deve permitir o acesso a bens ambientais, como terra e água, e a um meio ambiente equilibrado.

- Adequação cultural (CULT): A forma de construir a moradia e os materiais utilizados na construção devem expressar tanto a identidade quanto a diversidade cultural dos moradores e moradoras. Reformas e modernizações devem também respeitar as dimensões culturais da habitação.

Jannuzzi (2009) ressalta a importância de observar as propriedades desejáveis na construção de um indicador e relata que dentre essas propriedades o que mais importa é a 
relação recíproca entre o conceito e os indicadores propostos, a confiabilidade para as cifras calculadas e a inteligibilidade, não perdendo de vista que um "Indicador bom apenas indica; nunca substitui o conceito que Ihe originou" (Idem, p. 65).

Portanto, foi proposta a construção de um indicador simples que avalia a condição atual da moradia como ponto de partida para se discutir a política social, classificado segundo Jannuzzi (Idem, p. 32) como um indicador de Diagnóstico em que se viabiliza "a caracterização do contexto socioespacial em questão, a gravidade dos problemas sociais, a dimensão quantitativa das carências e demandas dos serviços públicos a atender".

As questões foram construídas objetivando a realização de análises estatísticas multivariadas, principalmente a Análise Fatorial exploratória (AFE). Essa ferramenta possibilita "definir a estrutura inerente entre as variáveis de análise" (HAIR JR et al., 2009). Em outras palavras, possibilita através das variáveis iniciais (as questões formuladas) extrair fatores, quais representariam as diretrizes da ONU, sendo cada fator um conjunto de questões com seus respectivos pesos (cargas fatoriais).

Os dados foram obtidos através de questionário estruturado aplicado em duas comunidades durante o ano de 2013, sendo o Assentamento Conquista, localizado no município de Tremembé-SP, e o bairro Ribeirão Grande, do município de Pindamonhangaba-SP (Figura 1). Durante o trabalho de campo, observou-se que seria importante realizar um censo em ambas as comunidades para que se conseguisse maior compreensão sobre suas particularidades, obtendo grupos amostrais de 169 e 167 casas, respectivamente.

Assim, apresentam-se os principais resultados da análise estatística descritiva dos dados dos questionários, para auxiliar na compreensão dos resultados da análise multivariada.

Figura 1: Localização das comunidades estudadas no estado de São Paulo.

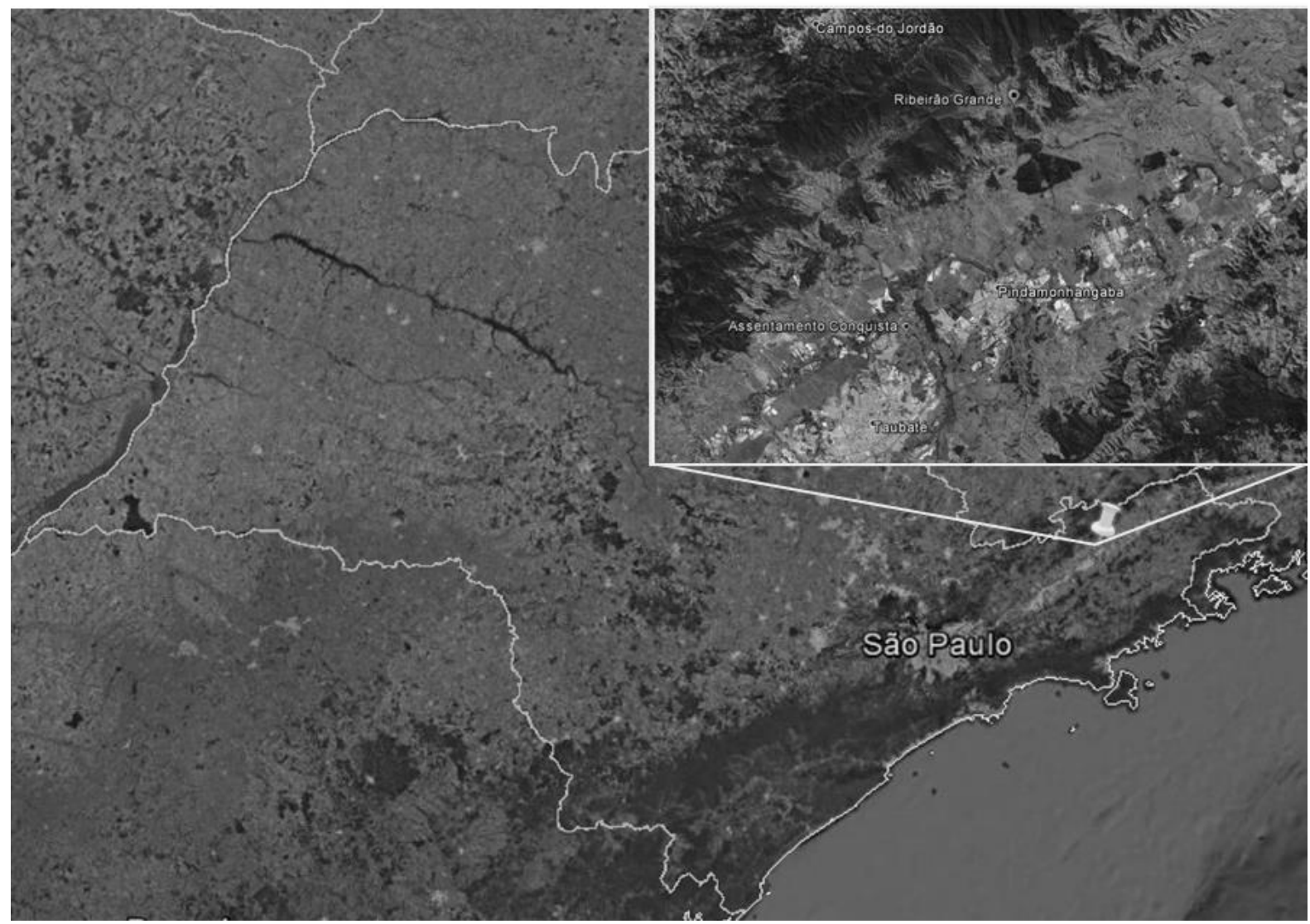

Fonte: Elaboração própria. Google Earth, 2017. 


\subsection{Assentamento Conquista}

Após a elaboração e o pré-teste do questionário contendo 168 questões, foi realizada no início de 2013 a sua aplicação em todo o Assentamento Conquista, conseguindo abarcar 170 famílias $(85 \%$ das casas habitadas no Assentamento), sendo 86 casas de titulares e 84 de agregados (Figura 2).

Figura 2: Localização das casas onde foram aplicados os questionários, Assentamento Conquista.

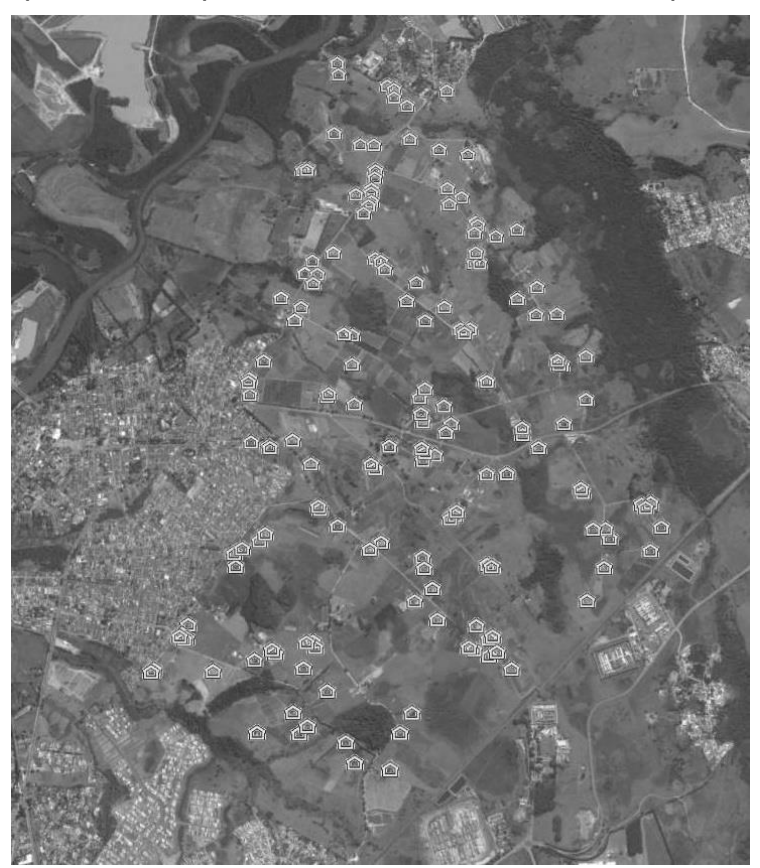

Fonte: Elaboração própria. Google Earth, 2014

A formação desse assentamento se deu através da ocupação em fevereiro de 1994 de uma área da Petrobrás localizada no município de Tremembé-SP por 100 famílias que já estavam em outros acampamentos no estado de São Paulo. Essas famílias continuaram acampadas em barracos de lona até março de 1995, quando ocorre à emissão de posse e o Assentamento fica sob-responsabilidade do Instituto Nacional de Colonização e Reforma Agrária (INCRA).

O Assentamento possui 1.290 ha e está divido em 103 lotes de em média 09 ha cada, além de possuir uma área destinada a Reserva Florestal e três lotes que servem como área comum e Sede.
Das casas dos agregados participantes da pesquisa, $67 \%$ são de filhos ou enteados dos titulares, $12 \%$ de irmãos, $4 \%$ de netos, $4 \%$ de pais, $4 \%$ de outros parentes e $10 \%$ de amigos ou conhecidos.

Os titulares dos lotes receberam recursos públicos para a construção e reforma de suas casas, sendo que os mesmos receberam $\mathrm{R} \$ 1.800,00$ em 1996 como parte do Crédito de Instalação e após 08 anos receberam duas de três parcelas de um total de $\mathrm{R} \$ 9.000,00$ para a construção da casa, repassadas pela Caixa Econômica Federal através do INCRA.

Dos titulares que tiveram acesso a esse recurso, $80 \%$ não estava satisfeito com o montante recebido e todos tiveram que usar de recurso próprio ou, em menor proporção, de recurso de parente ou ajuda de terceiros para conseguir investir na construção da casa.

Esse recurso previa, ainda, o pagamento de mão de obra, porém este sendo insignificante (menos de $10 \%$ do valor total) fez com que somente $29 \%$ dos titulares contrataram pedreiro, sendo que em 65 casas dos titulares foi utilizada mão de obra do próprio titular ou do casal e até mesmo dos filhos na construção, em 35 casas houve ajuda de parentes (filhos que já não moravam nessas casas) e 11 casas com ajuda de amigos, principalmente da igreja.

O tempo de construção das casas dos titulares foi de em média três anos para que conseguissem habitá-la, isso quer dizer que muitas vezes a família entrou na casa sem ter portas e janelas, no contrapiso e sem reboco. Além disso, quase todos os titulares ainda não havia terminado suas casas, com uma média de 12 anos em fase de construção.

As casas presentes no Assentamento Conquista tinham em média: 12 anos, $76 \mathrm{~m}^{2}, 05$ cômodos e 04 pessoas por casa (Figura 3). 0 tipo de material das paredes externas das casas, do piso e do forro pode ser observado na tabela 01 , com presença predominante da telha cerâmica. 
Todas as casas possuíam energia elétrica. A água para abastecimento da casa advinha de poço raso (cacimba ou caipira) em $87 \%$ das casas e em $69 \%$ das casas a quantidade de água não era suficiente em alguma parte do ano. Metade das casas entregava o lixo para a coleta pública e metade queimava, sendo que apenas metade das casas recebia coleta pública de lixo. Metade das casas possuía fossa séptica ou biodigestor e metade com fossa simples.

\subsection{Bairro Ribeirão Grande}

O bairro Ribeirão Grande localiza-se no município de Pindamonhangaba-SP (cidade vizinha a Tremembé), e está inserido na Área de Proteção Ambiental (APA) da Serra da Mantiqueira. Este é constituído principalmente pela terceira geração de famílias agricultoras provindas do estado de Minas Gerais que buscavam trabalho nas grandes fazendas, antigas produtoras de café.

Assim como em outras regiões do estado de São Paulo e do Brasil, as características desse bairro estão se modificando, quando pequenos lotes são vendidos para que sirvam como "segunda moradia", casas de veraneio, de fim de semana, além da presença de pousadas e restaurantes, consolidando um turismo rural na região. Muitas propriedades já não possuem

Figura 3: Exemplos de casas de titulares e agregados, Assentamento Conquista, 2013.
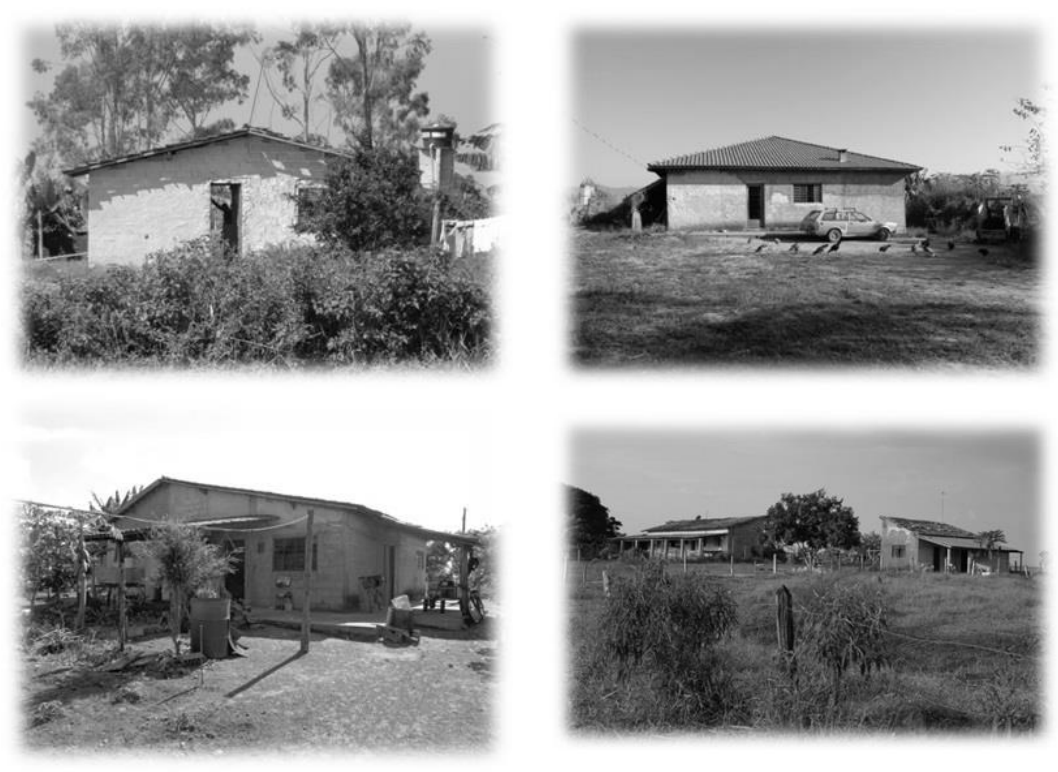

Tabela 1: Tipo de material das paredes externas, do piso e do forro das casas do Assentamento Conquista, 2013.

\begin{tabular}{lc}
\hline Parede & \% \\
\hline Alvenaria ou tijolo com reboco & 38 \\
Alvenaria ou tijolo sem reboco & 56 \\
Misto - alvenaria e madeira & 7 \\
\hline Piso & $\%$ \\
\hline Piso frio (cerâmica) & 56 \\
Contrapiso & 33 \\
Outros materiais (cimento queimado, tijolo à vista ou madeira) & 7 \\
\hline Forro & $\%$ \\
\hline Laje de concreto & 45 \\
Outros materiais (PVC, madeira ou gesso) & 14 \\
Sem forro & 37 \\
\hline
\end{tabular}


famílias que se dedicam à agricultura como atividade principal e algumas áreas estão sofrendo um adensamento populacional e se inserindo como parte da zona urbana do município (Figura 4).

A aplicação do questionário no bairro se deu após a avaliação dessa atividade no Assentamento, para que fosse possível realizar uma reflexão sobre as suas questões. Assim, um novo questionário foi formulado e adaptado para o bairro rural, a partir da realização de visitas ao local e entrevistas com os técnicos que atuam na região.
Figura 4: Localização das casas do Bairro Ribeirão Grande.

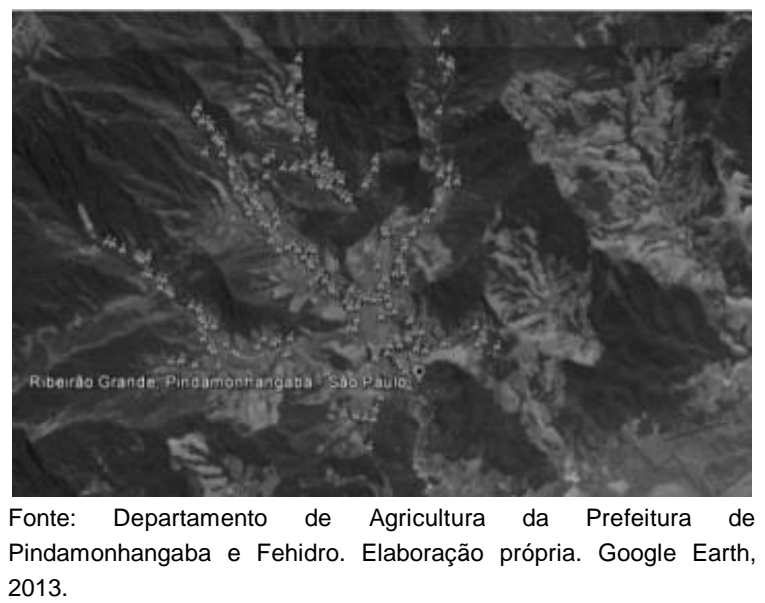

Figura 5: Exemplos de casas no Bairro Ribeirão Grande, 2013.

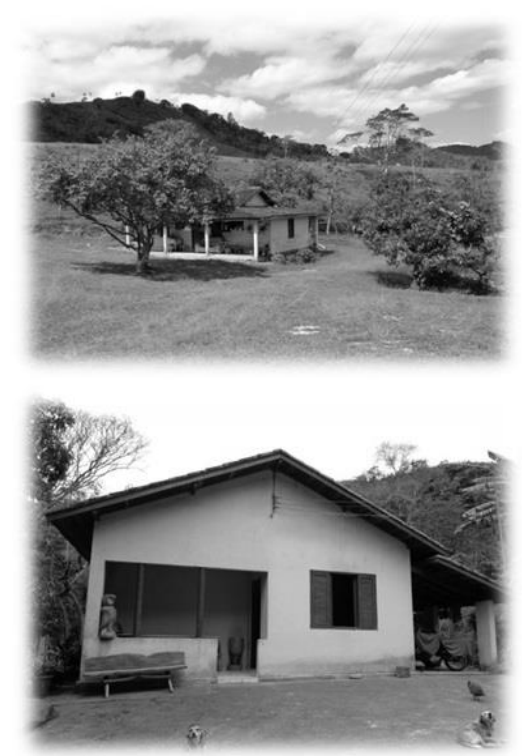

Com a presença das "segundas moradias", o critério utilizado na aplicação dos questionários foi entrevistar todos aqueles que moravam no bairro.

Após o pré-teste, o questionário contendo 209 questões foi aplicado no fim de 2013 em todo o bairro Ribeirão Grande, conseguindo abarcar 167 famílias, sendo 85 casas de proprietários, 28 de caseiros ou trabalhadores rurais, 18 casas cedidas e 36 alugadas ou em áreas arrendadas.

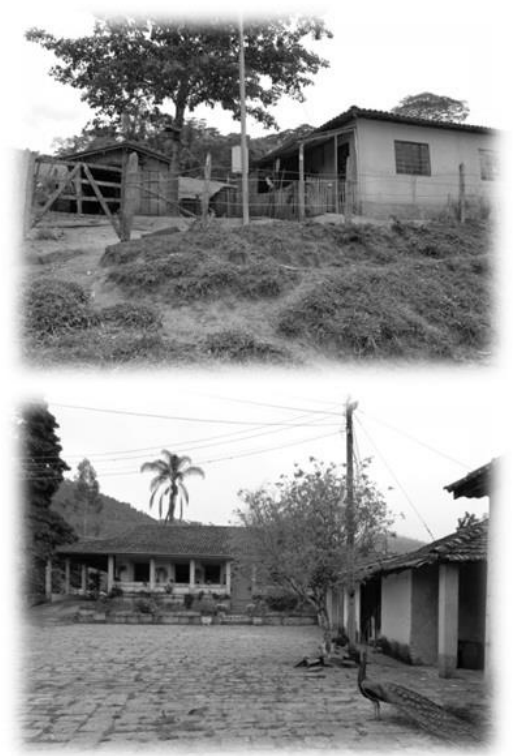

As casas do bairro estavam distribuídas entre casas das antigas fazendas e casas que foram construídas pelos filhos e netos dos antigos trabalhadores rurais (Figura 5). As famílias tinham em média 10 anos vivendo nessas casas, sendo que somente $38 \%$ dos entrevistados construíram suas casas.

Essas casas presentes no bairro Ribeirão Grande tinham em média: 27 anos, $95 \mathrm{~m}^{2}, 05$ cômodos e 03 pessoas por casa. Observou-se a predominância da parede feita de bloco ou tijolo com reboco (metade destas com bloco de concreto e a outra metade com tijolo maciço, baiano ou tijolo antigo) e o telhado feito de telha cerâmica (metade com telha Romana e metade 
Francesa). O tipo de piso e do forro encontrado nas casas pode ser observado na Tabela 2.

Somente duas casas não possuíam energia elétrica (sendo utilizado gerador). A água para abastecimento da casa advinha em $60 \%$ das casas de mina e em $31 \%$ de poço raso (cacimba ou caipira), sendo que em $12 \%$ dessas casas a quantidade de água não era suficiente em alguma parte do ano. Quase todas as casas entregava o lixo para a coleta pública e $35 \%$ dessas também entregava para reciclagem nas escolas do bairro. A coleta pública de lixo estava presente em $60 \%$ das casas. Mais da metade das casas possuía fossa séptica e $22 \%$ com fossa simples.

\section{Elaboração do Indicador de Direito à Moradia para o meio rural}

questão, o autor utiliza como exemplo uma investigação dos impactos sociais de um programa habitacional. Ressalta que provavelmente os indicadores objetivos apontem melhorias nas condições materiais de vida da população, mas que estas podem não estar representadas na satisfação dos entrevistados.

Sendo assim, a construção desse indicador sobre o direito à moradia no meio rural foi realizada a partir das questões subjetivas (de percepção do próprio sujeito entrevistado) contidas no questionário, onde na Tabela 3 é possível visualizar a quantidade de questões referentes a cada diretriz da ONU.

Objetivou-se, nesse trabalho, realizar a AFE pelo método de extração Componentes

Tabela 2: Tipo de material do piso e do forro das casas do Bairro Ribeirão Grande, Pindamonhangaba-SP, 2013.

\begin{tabular}{lc}
\hline Piso & \% \\
\hline Piso frio (cerâmica) & 58 \\
Cimento queimado & 23 \\
Outros materiais (madeira, contrapiso ou tijolo à vista) & 11 \\
\hline Forro & \% \\
\hline Madeira & 29 \\
Laje de concreto & 25 \\
PVC & 5 \\
Sem forro & 40 \\
\hline
\end{tabular}

Jannuzzi (2009, p. 20-21) apresenta que os indicadores podem ser definidos entre objetivos e subjetivos (quantitativos e qualitativos), descrevendo-os como referidos a "ocorrências concretas ou entes empíricos da realidade social", no caso dos indicadores objetivos, e a "avaliação dos indivíduos ou especialistas com relação a diferentes aspectos da realidade", no caso dos indicadores subjetivos. Esses últimos, "dotados de significados valorativos", podem não apontar as mesmas tendências dos indicadores objetivos e, para exemplificar essa
Principais, utilizando para todas as análises o software SPSS 17.0. Segundo Hair Jr et al. (2009), esta análise possibilita condensar a informação contida nas variáveis de entrada em um conjunto menor de variáveis estatísticas (fatores) com perda mínima de informação, ocorrendo assim redução de dados a um número suficiente de variáveis que continuam representando o conjunto original de variáveis e seus respectivos dados de entrada.

$\mathrm{Na}$ maioria dos casos, ainda segundo Hair Jr et al. (Idem), as soluções desta análise fatorial

Tabela 3: Questões de percepção referentes a cada diretriz da ONU.

\begin{tabular}{ccccccccc}
\hline & SEGPOSSE & DISPONIB & CUSTO & HABIT & GRUPOSVUL & LOCADEQ & CULT & TOTAL \\
\hline Assentamento & 8 & 15 & 14 & 12 & 3 & 25 & 4 & 81 \\
Bairro rural & 6 & 21 & 19 & 19 & 3 & 24 & 5 & 97 \\
\hline
\end{tabular}


sem executar rotação dos fatores não se mostra suficiente, sendo que a rotação melhora a interpretação final da análise apresentando uma estrutura fatorial mais simples. Com isso, optouse por utilizar nesta análise o método de rotação ortogonal Varimax, sendo requerido quando o objetivo é a redução de dados a um número menor de variáveis, porém que mantém a interdependência entre os fatores rotacionados resultando em uma separação mais clara dos fatores.

Com os dados tabulados, atribuíram-se valores numéricos padronizados para as respostas (por exemplo, bom - 3; médio - 2; ruim - 1; dados métricos). Foi necessário também atribuir valores numéricos para as respostas Não sabe ou não respondeu e Não se aplica, pois esta análise não possibilita a consideração dos objetos (sujeitos entrevistados) que possuem missing (dados perdidos). Além disso, considera-se que a resposta Não sabe ou não respondeu também possui valor atribuído para o sujeito, indicando a sua resposta e não a desconsiderando.

Com as variáveis ajustadas, deu-se início a análise estatística descritiva de seus dados, identificando aquelas que possuíam informações correlatas e que continham mais de $85 \%$ de respostas iguais entre as mesmas. Assim, foram geradas outras variáveis a partir do agrupamento dessas, pois é preciso haver variância significativa entre as variáveis para que seja possível a realização desse tipo de análise. Além disso, foram agrupadas também aquelas variáveis correlatas, mas que apresentavam graus elevados de respostas em Não se aplica e que por causa disso seriam descartadas nos próximos passos.

Após, observou-se aquelas variáveis que apresentavam $80 \%$ ou mais de suas respostas em apenas uma opção (categoria). Essas foram as primeiras variáveis desconsideradas na análise, pois não apresentam relevância estatística e impossibilitariam a execução da análise por não possuir variância interna.

Tendo feito isso, foi necessário ainda descartar aquelas questões com grau elevado de respostas em Não se aplica (50\% ou mais), avaliando-se a relevância de cada questão para o estudo a partir da sua representação para os sujeitos entrevistados na comunidade. Foram agrupadas ainda variáveis correlatas que continham mais de $70 \%$ das respostas iguais. Essas duas atividades foram realizadas com 0 objetivo de obter um conjunto de no máximo 33 variáveis para que se conseguisse consistência no modelo de saída da análise da AFE, aceitando-se um mínimo de 05 sujeitos por variável de entrada.

Todos os agrupamentos foram feitos a partir da soma das respostas das variáveis e a padronização do resultado na escala inicialmente utilizada (03 itens). Caso houvesse alguma resposta em Não sabe ou não respondeu ou Não se aplica, conservaram-se essas respostas para a nova variável criada.

Assim, a análise foi iniciada com 31 variáveis para o Assentamento e para o bairro rural, distribuídas entre as diretrizes da ONU de acordo com o que está apresentado na Tabela 4.

Antes de iniciar a AFE, foi feito um teste utilizando a Análise de Correspondências Múltiplas, pois esta tem como saída a representação gráfica de nuvens de pontos a qual propicia a identificação de grupos homogêneos de indivíduos segundo o conjunto de características observadas. Essa análise possibilita verificar sujeitos que apresentam um conjunto de respostas que não representam a comunidade, sendo considerados outliers no banco de dados, e se mantidos prejudicam a análise como um todo. Com isso, foram retirados dois sujeitos para o Assentamento

Tabela 4: Quantidade final de variáveis de entrada por diretriz da ONU.

\begin{tabular}{ccccccccc}
\hline & SEGPOSSE & DISPONIB & CUSTO & HABIT & GRUPOSVUL & LOCADEQ & CULT & TOTAL \\
\hline Assentamento & 3 & 7 & 5 & 5 & 1 & 9 & 1 & 31 \\
Bairro rural & 3 & 8 & 3 & 8 & 1 & 7 & 1 & 31 \\
\hline
\end{tabular}


Conquista e um para o bairro Ribeirão Grande.

Assim, deu-se início a Análise Fatorial exploratória com 0 método de extração Componentes Principais e método de rotação Varimax, com 31 variáveis, 167 sujeitos para o Assentamento e 166 sujeitos para o bairro rural.

Dado início à análise, foi feito o Teste de Esfericidade de Bartlett, o qual fornece a significância estatística de que existem correlações entre pelo menos algumas variáveis de entrada, sendo que a amostra precisa apresentar valor abaixo de 0,05. Também foi feita a verificação da adequação dos dados à análise fatorial através do método proposto por Kaiser-Meyer-Olkin - Medidas de Adequação da Amostra (MSA), utilizando o critério para aceitação valores acima de 0,50 tanto para o teste geral como para cada variável de entrada.

Caso fossem observadas variáveis com valores abaixo de 0,50 , foi feita a retirada da variável que apresentava o menor valor e iniciou-se a análise novamente.

Com todas as variáveis apresentando valores de MSA acima do aceitável, observou-se o poder de explicação de cada variável na formação do modelo através da tabela de Comunalidades. Para tanto, verificou-se quais variáveis apresentavam valores abaixo de 0,50 e retirou-se a variável que apresentava menor valor, iniciando a análise novamente.

Após, verificou-se se 0 modelo estava explicando boa parte dos dados, utilizando o critério para aceitação Variância Acumulada igual ou maior que $60 \%$ (variância explicativa de $60 \%$ da amostra). Além disso, para a determinação do número de fatores extraídos utilizou-se o critério de Kaiser (1960) apud Hair Jr et al (2009) considerando somente os fatores que possuíam Autovalor Inicial igual ou maior que 1.

Esta análise fatorial com rotação fornece uma
Matriz dos Componentes Rotacionados contendo os valores das cargas fatoriais de cada variável em cada fator extraído (a sua contribuição para cada fator). Segundo Hair Jr et al. (Idem), para um grupo amostral de 150 sujeitos aceita-se um valor mínimo de 0,45 de carga fatorial.

Como a proposta dessa pesquisa é a elaboração de um indicador simples, sendo considerado pela estatística como Escalas Múltiplas por possuir em seu interior a mensuração de várias dimensões de um mesmo conceito (HAIR JR et al., Idem), foi preciso realizar uma última análise para verificar a consistência interna do modelo de saída. Assim, foi feita uma avaliação do coeficiente de confiabilidade pelo teste de Alpha de Cronbach, utilizando como critério de aceitação valores iguais ou maiores que 0,60 (valor aceito para pesquisas exploratórias). Esse teste é feito para cada fator, observando somente as variáveis participantes do mesmo. Caso houvesse algum fator com valor abaixo do aceitável, retiravamse as variáveis que contribuíam somente com aquele fator, respeitando a retirada do fator que menos contribuía para a análise.

Com todas essas etapas realizadas, obteve-se a extração 06 fatores para o banco de dados do Assentamento e 05 fatores para o bairro rural. Os modelos estão explicando $75 \%$ e $68 \%$ da amostra, respectivamente, e com cargas fatoriais acima de 0,7 , portanto indicam estrutura bem definida com garantia de significância, além da confiabilidade dos fatores representando consistência interna no modelo.

$\mathrm{Na}$ Tabela 5 é possível verificar a distribuição das variáveis de saída por cada diretriz da $\mathrm{ONU}$, ressaltando que houve um equilíbrio na representação da maioria das diretrizes.

Porém, não houve nenhuma variável final que representasse "Não discriminação e priorização de grupos vulneráveis". Isso é decorrente de

Tabela 5: Quantidade final de variáveis de saída por cada diretriz da ONU.

\begin{tabular}{lcccccccc}
\hline & SEGPOSSE & DISPONIB & CUSTO & HABIT & GRUPOSVUL & LOCADEQ & CULT & TOTAL \\
\hline Assentamento & 0 & 3 & 4 & 3 & 0 & 4 & 1 & 15 \\
Bairros rurais & 3 & 3 & 3 & 3 & 0 & 3 & 1 & 16 \\
\hline
\end{tabular}


que essa diretriz foi iniciada somente com uma variável de entrada e esta não apresentou correlação aproximada com outra variável de outra diretriz, como ocorreu com a única variável de entrada de Adequação Cultural, impossibilitando a sua permanência.

Por fim, foram nomeados os fatores de saída de acordo com o seu conteúdo, observando o que descreve o conjunto de variáveis agrupadas em cada fator, representando as dimensões que compõem este indicador de direito à moradia, como consta na Tabela 6 para o Assentamento e Tabela 7 para o bairro Ribeirão Grande.

Observa-se que não permaneceram as variáveis relacionadas à Segurança de Posse para o caso do Assentamento, mas continuou presente para o bairro rural. Esse resultado é de suma importância para a compreensão das relações com os agentes externos que influenciam na vida dessas famílias.

Sabe-se através de vivências e entrevistas realizadas em Assentamentos que a questão da insegurança de posse é vivenciada pelos assentados e principalmente pelos agregados,

Tabela 6: Fatores extraídos, com seus valores de Alpha de Cronbach, suas respectivas variáveis com as cargas fatoriais e as nomenclaturas, para o banco de dados do Assentamento Conquista.

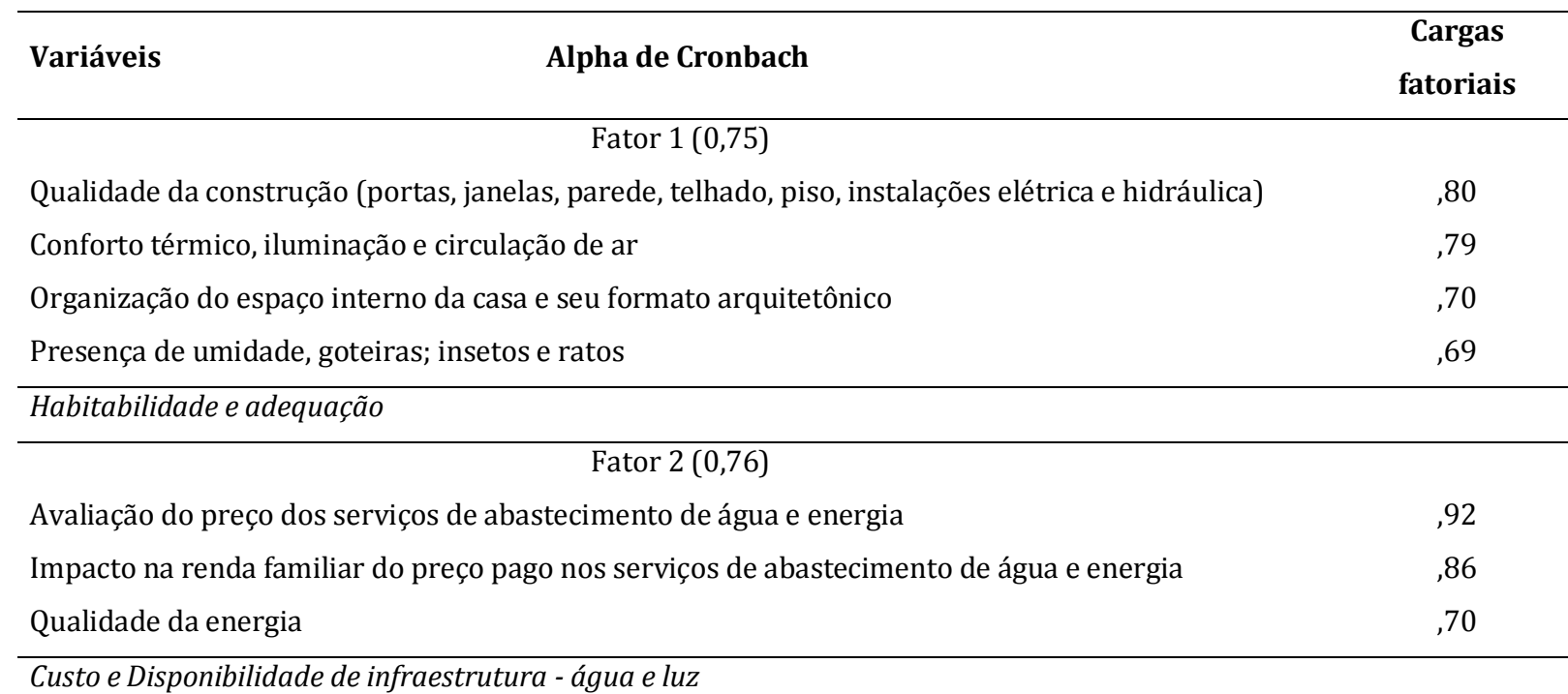

Fator $3(0,92)$

Distância das escolas públicas

Qualidade das escolas públicas

Disponibilidade e Localização de equipamentos públicos - Ensino

Fator $4(0,79)$

Distância do local de compra de alimentos e produtos de limpeza e farmácia

Distância dos serviços públicos de saúde

Localização adequada - fontes de abastecimento básicas e saúde

$$
\text { Fator } 5(0,72)
$$

Impacto na renda familiar do recurso gasto com a construção e/ou reforma da casa na renda

Impacto do recurso gasto com a construção e/ou reforma da casa na Saúde, Educação e Moradia

Custo acessível - construção e reforma da casa

$$
\text { Fator } 6(0,63)
$$


pois não há emissão de posse e sim um termo de concessão de uso da terra, além disso, há a indicação por parte dos órgãos responsáveis pelos assentamentos de reforma agrária de que não se podem construir outras casas para os parentes dos titulares, apesar da presença dessas casas em todos os assentamentos de reforma agrária do país. O Termo de Concessão de Uso deveria proporcionar a segurança de posse, porém existem outros elementos que permeiam a vida dessas famílias no assentamento, trazendo obrigações $e$ fazendo com que as suas funções sejam guiadas por questões políticas externas ao seu meio. Essas relações com os agentes externos quase sempre estão imbuídas de desconfiança e ocasionam na instabilidade e insegurança quanto ao futuro das famílias nos seus lotes.

Para o Assentamento Conquista, a segurança de posse não apresentou importância significativa no modelo final desse indicador de direito à moradia, outras questões tiveram mais peso e influenciaram o grau de conquista da mesma. Isso não quer dizer que a insegurança não estivesse presente, mas que a sua presença não está influenciando no conjunto das dimensões da conquista do direito à moradia adequada para essa comunidade.

Tabela 7: Fatores extraídos, suas respectivas variáveis com as cargas fatoriais e as nomenclaturas, para o banco de dados do Bairro rural Ribeirão Grande.

\begin{tabular}{|c|c|}
\hline Alpha de Cronbach & $\begin{array}{l}\text { Cargas } \\
\text { fatoriais }\end{array}$ \\
\hline \multicolumn{2}{|l|}{ Fator $1(0,75)$} \\
\hline Qualidade da construção (portas, janelas, parede, telhado, piso, instalações elétrica e hidráulica) & ,78 \\
\hline Conforto geral da casa & ,77 \\
\hline Presença de umidade, goteiras, insetos e ratos & ,75 \\
\hline Organização do espaço interno da casa e seu formato arquitetônico & 69 \\
\hline
\end{tabular}

Fator $2(0,84)$

Avaliação do preço pago de energia e aluguel $\quad 94$

Impacto na renda familiar do preço pago de energia $\quad 92$

Impacto na renda familiar do recurso gasto na construção, compra, reforma e/ou aluguel da casa

,73

Custo acessível

Fator $3(0,74)$

Distância do ponto de ônibus

Distância do posto de saúde

, 76

Qualidade do serviço de transporte municipal

Qualidade dos serviços públicos de saúde

, 70

Disponibilidade e Localização de serviços e equipamentos públicos - transporte e saúde

Fator $4(0,96)$

Qualidade das escolas públicas

Distância das escolas públicas

Disponibilidade e Localização de equipamentos públicos - Ensino

$$
\text { Fator } 5(0,63)
$$

Proteção pela lei (governo) contra a remoção 
Para o bairro rural, pensou-se inicialmente que esta questão não estaria presente, pois os mesmos são proprietários ou possuem contrato de trabalho, arrendamento ou mesmo aluguel. Porém, as perguntas foram mantidas no préteste e observou-se logo no início de que havia a insegurança de posse ou de permanência na casa devido a questões como: o bairro estar inserido numa APA (casas construídas em locais impróprios ou em lotes com menos de 20 ha), a proposta de criação do Parque da Serra da Mantiqueira (ameaça de retirada das casas e das famílias do local), a instabilidade trazida pela relação de trabalho ou arrendamento com a concessão da casa, ou mesmo pela instabilidade na relação de contrato de aluguel (se o dono demanda a casa ou aumenta o preço do aluguel, etc.).

Com essa diretriz sendo representada, observase a partir desses resultados que a questão da insegurança de posse está influenciando a conquista do direito à moradia adequada para as famílias que vivem no bairro Ribeirão Grande, trazendo à tona a importância de se refletir sobre as relações com os agentes externos permeadas pela função ambiental colocada à comunidade e pelas novas relações de trabalho ou aluguel versus moradia.

Quanto aos fatores extraídos, observa-se que o fator Habitabilidade e adequação se faz presente e está localizado com o mesmo grau de importância para os dois modelos, demonstrando que as condições habitacionais são o que mais influencia a conquista do direito à moradia para as famílias de ambas as comunidades.

$\mathrm{Na}$ questão do Custo acessível, esse esteve presente em segundo lugar no grau de importância para a conquista do direito à moradia para ambos os modelos. Porém, há uma diferença para o caso do Assentamento onde houve a separação desse custo em gastos mensais (Fator 2) e gastos com a construção e reforma da casa (Fator 5), sendo que o Fator 2 é acrescido, ainda, da variável sobre a qualidade do fornecimento de energia.
Observa-se que os gastos mensais (Fator 2) são postos com maior grau de importância do que os impactos dos gastos com a construção e reforma da casa (Fator 5). Essa alocação do custo para obtenção da casa no Fator 5 traz a necessidade de se refletir sobre o impacto do mesmo para a conquista do direito à moradia, pois sabe-se, a partir das entrevistas realizadas no Assentamento, que há uma privação das necessidades básicas para a construção da casa, mesmo com a presença do recurso do Estado. As famílias relatavam as dificuldades passadas principalmente no momento inicial da construção da casa (até a finalização da laje), as quais deixaram marcas na trajetória de vida dessas famílias e traz consequencias para as condições atuais da casa quanto a sua habitabilidade, mas também para os aspectos socioculturais enquanto possibilidades de representação de identidade na casa.

Acredita-se que um dos motivos desse grau de importância não estar representado no modelo final esteja no fato de que o momento da pesquisa não coincide com esse momento inicial de construção. Após a entrada das famílias nas casas, mesmo que inconclusas, o objetivo de se orientar recurso para a construção da casa é substituído por outras necessidades básicas, fazendo com que no momento de se refletir sobre o que já se passou, as necessidades mais urgentes e atuais são postas ao pesquisador, como os gastos mensais e a qualidade do fornecimento de energia.

Para o Bairro rural, essa diretriz foi representada por um único fator (Fator 2), porém isso é justificado também pela presença do custo do aluguel e arrendamento em $22 \%$ dos entrevistados, além dos $38 \%$ que construíram suas casas e dos $20 \%$ que realizam reformas nas casas cedidas.

A questão dos serviços públicos de Ensino (Fator 3 para o Assentamento e Fator 4 para o Bairro), também presentes nos dois modelos, apresenta menor grau de importância do que a saúde e transporte para o caso do Bairro rural, isso pode ser resultante de que somente $36 \%$ das famílias entrevistadas tinha criança na 
escola pública, fazendo com que os serviços de saúde e transporte apareçam com maior grau de importância no dia a dia das famílias.

O Fator 3 obtido para o Bairro rural apresenta a questão da disponibilidade e localização de serviços de transporte junto com a questão da saúde, fazendo com que se reflita sobre que ambos os serviços são requeridos em igual importância para esses sujeitos. Já para o Assentamento, essas variáveis aparecem em fatores separados, colocando a importância da distância das fontes de abastecimento básicas e saúde no Fator 4 e os serviços de transporte como último fator do modelo obtido (Fator 6). Isso é facilmente justificado pelo fato de que o Assentamento faz divisa com a área urbana da cidade de Tremembé-SP e o Bairro rural está há mais de $20 \mathrm{~km}$ do centro da cidade de Pindamonhangaba-SP, portanto há uma dependência entre se locomover e adquirir produtos para o caso do Bairro rural. No Assentamento, a proximidade faz com que os assentados utilizem outros tipos de transporte, como bicicleta, carroça e até mesmo o carro próprio.

Apesar dessas pequenas diferenças entre as comunidades, a questão do acesso e da qualidade desses serviços públicos está influenciando a garantia do direito à moradia para essas famílias, reforçando a importância de se observar a infraestrutura local quando se trata de uma moradia digna.

Como já citado anteriormente, o Fator 5 para o Bairro rural concentra as variáveis sobre a segurança de posse, constatando-se a importância dessa diretriz para o bairro, mas, ao posicioná-la como último fator, demonstra que as outras diretrizes são mais determinantes para a conquista do direito à moradia nas condições atuais dessas famílias.

\section{Conclusões}

A partir dos dados dos questionários, foi possível realizar a análise estatística e identificar o que está influenciando a conquista do direito à moradia para o Assentamento Conquista e para o bairro Ribeirão Grande. Os fatores extraídos apresentam variáveis que contêm sentidos comuns e representam cinco das sete diretrizes da ONU. Ao comparar as duas realidades estudadas, observa-se que muitas das variáveis de saída são as mesmas ou apresentam similaridades entre os modelos obtidos, constatando que a atuação do Estado no Assentamento não influenciou consubstancialmente no processo de construção das casas.

A proposta de elaboração desses indicadores tinha como finalidade apresentar uma ferramenta de diagnóstico da realidade local, considerando a possibilidade de que este assunto possa ser aprofundado e abrangido em outros estudos.

A diretriz relacionada à Adequação Cultural finalizou com uma variável participante, assim como a diretriz "Não discriminação e priorização de grupos vulneráveis". Na elaboração do questionário já havia a preocupação com a dificuldade de inserção de questões que reproduzissem uma dimensão subjetiva $e$ particular do meio em valores mensuráveis. Houve a tentativa com algumas questões elaboradas após o pré-teste realizado no Assentamento e, para o caso do bairro rural, após a avaliação da aplicação dos questionários no Assentamento, porém suas respostas não apresentaram a relevância estatística necessária para serem inseridas nessa análise. Um novo estudo é preciso ser feito, com base em pesquisa de campo, para elaborar novas questões que represente e abarque a profundidade requerida nessa diretriz.

Para o caso da "Não discriminação e priorização de grupos vulneráveis", houve apenas três questões que foram agrupadas em uma única variável de entrada, seria necessário também refletir sobre as possibilidades de questões que pudessem aprofundar e alcançar a importância que essa dimensão apresenta para a conquista do direito à moradia no meio rural.

\section{Agradecimentos}

As autoras são muito agradecidas às famílias do Assentamento Conquista e do Bairro Ribeirão Grande. Este trabalho faz parte do 
Projeto "Entraves e potencialidades para a conquista do direito à moradia no meio rural através da análise de um bairro rural e um assentamento de reforma agrária" financiado pelo $\mathrm{CNPq}$ (Conselho Nacional de Desenvolvimento Científico e Tecnológico) e pela FAPESP (Fundação de Amparo à Pesquisa do estado de São Paulo), qual também forneceu bolsa de doutorado à primeira autora.

\section{Referências}

BARBO, A. R. C; SHIMBO, I. Uma reflexão sobre o padrão mínimo de moradia digna no meio urbano brasileiro - estudo dos métodos de cálculo da Fundação João Pinheiro e da Fundação Seade. R. B. Estudos Urbanos e Regionais, v. 8, n. 2, p. 75-94, nov. 2006.

CENDRERO UCEDA, A. Indicadores de desarrollo sostenible para la toma de decisiones. Naturzale, n. 12, p. 5-25, 1997.

HAIR JR, J. F. et al. Análise multivariada de dados. 6 ed. Porto Alegre: Bookman, 2009. $688 \mathrm{p}$.

HENKES, S. L. Dos reflexos jurídicos, políticos, sociais e ambientais da constitucionalização do direito à moradia. Revista Jus Navigandi, Teresina, ano 9, n. 815, set. 2005.

JANNUZZI, P. M. Indicadores sociais no Brasil. 4 ed. Campinas: Editora Alínea, 2009. 141 p.

MILAGRES, M. O. Direito à moradia. São Paulo: Atlas, 2011. $225 \mathrm{p}$.

RELATORIA ESPECIAL DO CONSELHO DE DIREITOS HUMANOS DA ONU. O que é direito à moradia? Disponível em: <http://direitoamoradia.org>. Acesso em: 16 jun. 2012.

SARLET, I. W. O direito fundamental à moradia na constituição: algumas anotações a respeito de seu contexto, conteúdo e possível eficácia. Revista Brasileira de Direito Público, Belo Horizonte, ano. 1, n.02, p. 65-119, jul./set. 2003.

SOUZA, S. I. N. Direito à moradia e de habitação: análise comparativa e suas implicações teóricas e práticas com os direitos da personalidade. 2 ed. São Paulo: Editora Revista dos Tribunais, 2008. $366 \mathrm{p}$.

UN-HABITAT; OHCHR. Monitoring housing rights: developing a set of indicators to monitor the full and progressive realization of the human right to adequate housing. Nairobi: UN-Habitat; OHCHR, 2003. 109 p. 